\title{
Cyber Dating Abuse: Investigating Digital Monitoring Behaviors Among Adolescents From a Social Learning Perspective
}

\author{
Joris Van Ouytsel, MSc a,b (joris.vanouytsel@uantwerpen.be) \\ Koen Ponnet, PhD a,c (koen.ponnet@uantwerpen.be) \\ Michel Walrave, PhD ${ }^{a}$ (michel.walrave@uantwerpen.be)
}

\author{
Affiliations: \\ ${ }^{a}$ Department of Communication Studies, University of Antwerp, Sint-Jacobsstraat 2, 2000 Antwerp, \\ Belgium \\ ${ }^{\mathrm{b}}$ Department of Ob/Gyn, UTMB Health, 301 University Blvd, Galveston, TX 77555-0587, USA \\ c Department of Communication Studies, Ghent University, Korte Meer 11, 9000 Ghent, Belgium
}

Corresponding author: Joris Van Ouytsel, Sint-Jacobsstraat 2, 2000 Antwerp - Belgium, joris.vanouytsel@uantwerp.be, +32 - 32655279

Key words: cyber dating abuse; adolescents; social learning theory; dating violence;

Funding Source: The study was supported by the Research Fund of the University of Antwerp (BOF DOC PRO 2013 - 41/FA040300/FFB130145). From October 2015, the work of Joris Van Ouytsel is supported by a PhD Fellowship of the Research Foundation - Flanders (FWOAspirant). The study design, data collection, analysis, interpretation of the data, writing of the report and the decision to submit the article for publication were the sole responsibility of the authors and were in no way influenced by the Research Fund of the University of Antwerp or the Research Foundation - Flanders.

Financial Disclosure: The authors have indicated they have no financial relationships relevant to this article to disclose.

Acknowledgments: The authors would like to thank the undergraduate students Lien Maldoy, Esther Sikkens, and Moniek Wallink for their assistance with the data collection.

Conflict of Interest: The authors report no conflicts of interest.

\section{Biographical statements:}

\section{Joris Van Ouytsel}

Joris Van Ouytsel, MSc. is a researcher at the research group MIOS, University of Antwerp. He focuses his research on cyber dating abuse, sexting, and online self-disclosure among adolescents. His work is supported by a PhD Fellowship of the Research Foundation Flanders (FWO-Aspirant).

\section{Koen Ponnet}

Koen Ponnet, Ph.D. in Psychology, is an assistant professor at the Department of Communication Sciences of Ghent University. He also teaches at University of Antwerp . His main research interests are the (mental) health, risk and problem behavior of adolescents and adults, both off-line and on-line. In his research, he pays attention to the situation of vulnerable groups.

\section{Michel Walrave}


Michel Walrave, Ph.D. in Social Sciences, is a professor at the Department of

Communication Studies of the University of Antwerp. He is responsible for the research group MIOS. His research is centered around online self-disclosure and privacy. He investigates adolescents' and adults' online disclosure of personal information to other individuals or companies, and related opportunities and risks. 
Cyber Dating Abuse:

Investigating Digital Monitoring Behaviors Among Adolescents From a Social Learning Perspective 


\begin{abstract}
Just as with other forms of abuse such as bullying, dating violence is no longer limited to physical spaces. Several forms of dating violence can also be perpetrated by means of technology. Few studies have used a theoretical perspective to investigate cyber dating abuse. This study addresses this gap in the literature by focusing on the perpetration of digital monitoring behaviors - a form of cyber dating abuse - from a social learning perspective. We investigate the extent to which perceived social norms about cyber dating abuse, witnessing controlling behaviors among parents, and endorsing gender stereotypes are linked with adolescents' engagement in digital monitoring behaviors. The study draws on data from 466 secondary school students $(71.0 \%$ girls, $n=331)$ between 16 and 22 years old $(M=17.99$ years; $S D=.92$ ) in Flanders, Belgium, who were in a romantic relationship. Linear regression analysis indicates that being female, being older, the perceived social norms of peers, the endorsement of gender stereotypes, and having observed intrusive controlling behaviors by the father are significantly and positively related to adolescents' perpetration of digital monitoring behaviors. The findings have implications for practice and underscore the need for prevention efforts to address and lower the influence of these perceived social norms. Further implications include the need for prevention efforts to focus on diminishing the impact of gender-stereotypical attitudes and the influence of witnessing controlling behaviors within the family context on cyber dating abuse perpetration.
\end{abstract}

Keywords: cyber dating abuse; adolescents; social learning theory; dating violence; 


\section{Cyber Dating Abuse:}

\section{Investigating Digital Monitoring Behaviors Among Adolescents From a Social Learning Perspective}

Just as with other forms of abuse such as bullying, dating violence is no longer limited to physical spaces (Borrajo, Gámez-Guadix, Pereda, \& Calvete, 2015). Several forms of dating violence can also be perpetrated by means of technology. Zweig, Lachman, Yahner, and Dank (2014, p. 1306) define cyber dating abuse as "control, harassment, stalking, and abuse of one's dating partner via technology and social media." Studies have found that the prevalence rates of cyber dating abuse victimization among adolescents range between $22.2 \%$ (Temple et al., 2015) and 26.3\% (Zweig, Dank, Yahner, \& Lachman, 2013). Zweig et al. (2013) also found that $11.8 \%$ of youth had engaged in cyber dating abuse perpetration. In a sample of sixth graders, Peskin et al. (2017) found that $15 \%$ of the participants had perpetuated cyber dating abuse at least once in their lifetime.

Current research has mainly focused on how cyber dating abuse victimization and perpetration are related to other types of risk behavior. Cyber dating abuse victimization has been cross-sectionally associated with negative emotional health outcomes such as depressive symptoms, feelings of anger, and hostility (Zweig et al., 2014). Moreover, victims have been found to engage more often in health-risk behaviors such as heavy episodic drinking (Van Ouytsel, Ponnet, Walrave, \& Temple, 2016) and contraceptive non-use (Dick et al., 2014; Van Ouytsel et al., 2016). Cyber dating abuse perpetration has been cross-sectionally associated with substance use, sexual behavior and sexually risky behavior, and poorer selfreported physical health. Perpetration was also associated with bullying victimization and perpetration (Van Ouytsel et al., 2017). 
Although offline and online forms of dating abuse are associated with each other, they also differ from each other in several ways, which warrants additional research into the digital behavior. As opposed to traditional dating violence, the perpetrators and victims of cyber dating abuse do not have to be present in the same time and space. Cyber dating abuse can occur 24/7; therefore, the victims might experience difficulties with escaping from it and distancing themselves from the abuse and the perpetrators (Borrajo et al., 2015; Peskin et al. 2017; Stonard et al., 2015; Van Ouytsel, Walrave, Ponnet, \& Temple, 2016). Furthermore, because of the absence of nonverbal cues such as intonation, facial expressions, and body language, digital messages carry a higher potential to be misinterpreted and to subsequently create misunderstandings (Heirman \& Walrave, 2008). Likewise, the absence of a direct emotional response by the victim (such as a shaking head, tears, or being upset) might lower the inhibitions of perpetrators to engage in abusive behaviors and to accurately assess the damage of their actions (Heirman \& Walrave, 2008; Suler, 2004). A higher chance for repeated victimization exists because of the permanent nature and sharing of digital messages (Peskin et al., 2017). Additionally, checking on the romantic partner through digital media might feel more socially acceptable and less like a violation of trust for the perpetrators than offline forms of surveillance behaviors, such as opening the mail or searching through the bags of a romantic partner (Utz \& Beukeboom, 2011).

Qualitative studies have identified the digital monitoring and intrusive controlling of a romantic partner as one of the most common types of cyber dating abuse among adolescents (Lucero, Weisz, Smith-Darden, \& Lucero, 2014; Stonard, Bowen, Walker, \& Price, 2015; Van Ouytsel, Van Gool, Walrave, Ponnet, \& Peeters, 2016). The forms of digital monitoring behaviors that emerged in a study by Stonard et al. (2015, p. 10) included "checking messages and online accounts," "demanding passwords to phone or online accounts," “" deleting ex-partners from online accounts," and "obsessive checking through excessive 
contact." Baker and Carreño (2016) found that experiencing feelings of jealousy often led adolescents to engage in digital monitoring and controlling behaviors. Online partner surveillance among teenagers and young adults has also been associated with attachment anxiety (Reed, Tolman, \& Safyer, 2015; Reed, Tolman, Ward, \& Safyer, 2016).

Victimization of digital monitoring behaviors has been associated with the amount of social networking site use and with unsafe Internet use (Van Ouytsel, Ponnet, \& Walrave, 2016). In line with research showing that psychological forms of offline dating violence are linked to physical dating violence (Baker \& Stith, 2008), several studies have observed that cyber dating abuse and offline forms of dating violence are reciprocal and often co-occur (Dick et al., 2014; Temple, Choi, Brem, et al., 2016; Yahner, Dank, Zweig, \& Lachman, 2014).

The ease with which cyber dating abuse can be perpetrated through digital technologies as well as the differences in nature between cyber dating abuse and offline forms of dating violence warrant additional research on risk factors for perpetration. As Peskin et al. (2017) noted, most of the previous studies on traditional forms of dating violence do not account for online forms of dating abuse, which is critical given teenagers' frequent technology use. Moreover, current research on cyber dating abuse is largely descriptive in nature and lacks a theoretical approach with which to better understand the context in which cyber dating abuse takes place and to design effective prevention efforts. To address this gap in the literature, the aim of this study is to investigate digital monitoring behaviors from a social learning perspective. Applying this theoretical framework will allow us to study how the social norms of peers, adolescents' own attitudes (i.e., the endorsement of gender stereotypes), and adolescents having observed controlling behaviors within the family are associated with cyber dating abuse perpetration. Given that peers are an important source of influence within adolescents' lives (Steinberg, 2011), the social learning theory constitutes an appropriate framework with which to investigate cyber dating abuse because it captures 
both the adolescents' attitudes toward the behavior as well as important social influences during this developmental period. The application of a theoretical framework to investigate cyber dating abuse perpetration will allow the identification of the theoretical variables associated with engaging in the behavior and provide additional insight into the context in which it takes place. The identification of influential factors in cyber dating abuse perpetration can, in turn, help prevention and intervention efforts to effectively address cyber dating abuse perpetration.

\section{Social Learning Theory}

The aim of social learning theory is to explain why individuals engage in a deviant behavior (Akers \& Jennings, 2009; Bandura, 1977). This theoretical perspective explains how beliefs and interactions with role models, such as parents or peers, could drive an individual's engagement in a particular behavior (Akers et al., 2009). One source of learning comes from associating with peers who hold positive attitudes toward the deviant behavior. Following social learning theory, it is expected that individuals will be more likely to engage in a certain deviant behavior if they perceive the social norms of others regarding that behavior as positive (Akers \& Jennings, 2009). Another source of learning comes from observing and imitating this behavior (Akers \& Jennings, 2009). Individuals observing others perform a (deviant) behavior might feel inclined to engage in the same behavior. Furthermore, the individuals' own attitudes toward a behavior, which might also be shaped by social influences such as media exposure, will influence whether they will perform that behavior (Akers \& Jennings, 2009). In this study, we will investigate whether endorsement of gender stereotypes is associated with cyber dating abuse perpetration. A final component of social learning theory comprises the outcomes that an individual expects when performing a certain behavior. These outcomes can consist of social approval or other perceived advantages of 
engaging in a certain behavior. Moreover, the reinforcement component can also include the potential legal consequences associated with engaging in a certain behavior, which can discourage an individual from engaging in it (Akers \& Jennings, 2009; Akers, Krohn, LanzaKaduce, \& Radosevich, 1979).

In the following paragraphs, we will review how social influences impact adolescents' engagement in dating violence. Moreover, hypotheses will be formulated with regard to our own study assessing the extent to which the constructs of social learning theory are associated with adolescents' engagement in digital monitoring behaviors, which are a form of cyber dating abuse.

\section{Social Norms About Dating Violence}

In terms of dating violence, the differential association component of social learning theory posits that individuals will be more likely to engage in dating violence if they have peers who endorse these forms of abusive behaviors (Akers \& Jennings, 2009). Several studies have looked into the transmission of group values on dating violence perpetration. Sellers, Cochran, and Branch (2005) found that college students who perceived that important others, such as parents or best friends, would approve of the use of physical dating violence against a romantic partner were more likely to perpetrate dating violence themselves. Cochran, Maskaly, Jones, and Sellers (2015) found that the more college students perceived that dating violence occurred among their peers and that their friends would approve of dating violence, the more likely they were to perpetrate dating violence against their partner. Among adolescent samples, several studies found positive associations between the extent to which male adolescents perceive their peers as being involved in dating violence and their own dating violence perpetration (Arriaga \& Foshee, 2004; Foshee, Linder, MacDougall, \& Bangdiwala, 2001; Reed, Silverman, Raj, Decker, \& Miller, 2011). 
Outside of the context of research on offline dating violence, several studies have found that group norms significantly impact adolescents' engagement in online aggressive behaviors such as cyberbullying (Heirman \& Walrave, 2008; Sasson \& Mesch, 2017) and online deviant behaviors such as sexting behavior (Van Ouytsel, Ponnet, Walrave, \& d'Haenens, 2017). Following this previous research on the impact of perceived social norms on adolescents' engagement in offline forms of dating violence and online risk behaviors, we expect similar relationships with regard to cyber dating abuse. Therefore, we formulate the following hypothesis:

H1: There is a positive relationship between perceiving the social norms with regard to digital monitoring behaviors among peers as positive and adolescents' engagement in digital monitoring behaviors.

\section{Witnessing Interparental Controlling Behaviors}

Certain behaviors can also be influenced by observational learning from role models such as parents, who can function as sources of imitation (Akers \& Jennings, 2009; A. Bandura, Ross, \& Ross, 1962). The cycle of violence hypothesis, also known as the intergenerational transmission of violence, states that children who have been victimized by violence or witnessed it are more likely to become perpetrators themselves as they grow up (Heyman \& Slep, 2002; Manchikanti Gómez, 2011; Sellers et al., 2005). Parents often function as important role models, and children and adolescents who witness violence in the household when they grow up might believe that this is an appropriate way to express anger and resolve conflicts (Foshee et al., 2001; Manchikanti Gómez, 2011; Sellers et al., 2005; Wolf \& Foshee, 2003). Consequently, adolescents might act the same way in their own relationships (Dardis, Dixon, Edwards, \& Turchik, 2015). 
A substantial body of research on offline forms of dating violence has focused on the impact of that violence within the family. Witnessing interparental violence-which also includes psychological violence such as intrusive, controlling behaviors - can augment the probability that adolescents will engage in dating violence themselves. Several studies have found that interparental violence is linked with adolescents perpetrating offline dating violence (Arriaga \& Foshee, 2004; Foshee, Bauman, \& Linder, 1999; Malik, Sorenson, \& Aneshensel, 1997; O'Keefe, 1997; Schwartz, O'Leary, \& Kendziora, 1997). Witnessing interparental violence was also linked to having positive outcome expectations of dating violence as well as endorsing positive norms toward dating violence among adolescents (Foshee et al., 1999). Following this line of research, a similar relationship might exist between witnessing parents' intrusive controlling behaviors offline and online and adolescents' own controlling behaviors in romantic relationships. We therefore hypothesize the following:

H2a: There is a positive relationship between the frequency of adolescents having observed their father controlling their mother and adolescents' own engagement in digital monitoring behaviors.

$\mathrm{H} 2 \mathrm{~b}$ : There is a positive relationship between the frequency of adolescents having observed their mother controlling their father and adolescents' own engagement in digital monitoring behaviors.

\section{Attitudes: Gender Stereotypes}

Another important component of social learning theory is the attitudes toward a deviant behavior. In this study we will look at whether the endorsement of gender stereotypical beliefs is associated with cyber dating abuse perpetration. An individual's 
approving or disapproving attitudes toward a behavior play a role in whether the individual will engage in that behavior (Akers \& Jennings, 2009; Sellers et al., 2005). Several studies have found, for instance, that the acceptance of positive norms toward offline dating violence is linked with perpetration (Cochran et al., 2015; Foshee et al., 2001; Malik et al., 1997; Schwartz et al., 1997; Sears, Sandra Byers, \& Lisa Price, 2007; Shen, Chiu, \& Gao, 2012; Simon, Miller, Gorman-Smith, Orpinas, \& Sullivan, 2010; Temple, Choi, Elmquist, et al., 2016).

Attitudes that facilitate dating violence are not just limited to a specific set of norms regarding dating violence but can also include the endorsement of other beliefs that are permissive of intimate partner violence, such as gender stereotypical beliefs or genderequitable attitudes (Foshee et al., 2001; Sellers et al., 2005). These attitudes are often formed within the home by observing parents or other family members, or by being exposed to media content (Lichter \& McCloskey, 2004). The findings on the role of gender stereotypical beliefs in perpetrating teenage dating violence are equivocal. Foshee et al. (2001) found that the endorsement of gender stereotypical beliefs was not significantly associated with dating violence perpetration, whereas other studies found that male adolescents who had more gender stereotypical beliefs were more likely to be perpetrators of dating violence than those who held lower levels of gender stereotypical beliefs (McCauley et al., 2013; Reed et al., 2011; Reyes, Foshee, Niolon, Reidy, \& Hall, 2016). Following the latter studies that found a relationship between the endorsement of gender stereotypical beliefs and dating violence perpetration, we formulate the following hypothesis, in which we expect a similar association between the endorsement of gender stereotypes and engagement in digital monitoring behaviors: 
H3: A higher endorsement of gender stereotypes has a positive relationship with engagement in digital monitoring behaviors

In summary, few studies have used a theoretical perspective to investigate digital monitoring behaviors. The aim of the present study is to investigate the extent to which the perceived social norms about cyber dating abuse, witnessing controlling behavior among parents, and the endorsement of gender stereotypes are linked with adolescents' engagement in digital monitoring behaviors. The theoretical model is summarized in Figure 1.

Insert Figure 1 about here

\section{Method}

\section{Sample and Procedures}

Between March and May 2015, 1,187 students (61.3\% girls, $n=728)$ from seven secondary schools in Flanders, Belgium, participated in the [name of the study removed for the purpose of blind peer review]. At every school, students from the last and second-to-last year of secondary education participated. In one school, students from a vocational "seventh year" of secondary school education also participated in the survey. In this study, we report the data from a subsample of students who indicated that they were "in a romantic relationship with someone or had a romantic partner" $(39.3 \%$ yes, $n=466)$. All of the students in the final sample $(71.0 \%$ girls, $n=331)$ were between 16 and 22 years old $(M=$ 17.99 years, $S D=0.92$ ).

Formal consent from the school's principal was obtained prior to the study, and passive consent from the participants was obtained. Before starting the survey, the respondents received a letter explaining the purpose and procedures of the study. The 
participants were also assured that their answers would remain anonymous and that they could withdraw their participation at any time. Furthermore, the letter included information about two free helplines from which the respondents could receive more information about the themes of the survey. To enhance their feeling of privacy, the participants were asked to return their questionnaires in a sealed envelope. The study's protocol was approved by the Ethical Committee of the authors' institution.

\section{Measures}

Dependent variable. The cyber dating abuse perpetration scale (Cronbach's $\alpha=.76$ ) consisted of four items adapted from the control dimension of the Cyber Dating Abuse Questionnaire (Borrajo et al., 2015). The items measured whether the respondents had engaged in digital monitoring of their current romantic partner in the six months prior to the survey. It assessed whether (a) the respondents had accessed e-mail messages and messages on the partner's cell phone and social networking accounts without his or her consent, (b) whether they checked the "last seen" feature on apps such as Facebook Messenger or WhatsApp to control their partner, (c) whether they had sent messages via the Internet or mobile phone to check what their partner was doing and who they were with, and (d) whether they sent messages or called several times in a row (five/10/20/30 times an hour) to control where their partner was and with whom. The scale ranged from $1=$ never to $5=$ very often. The items were combined to form the dependent variable in our analyses $(M=1.70 ; S D=$ .77). The percentages of adolescents that had engaged in the behavior at least once are summarized in Table 1.

Insert Table 1 about here 


\section{Independent variables.}

Perceived social norms with regard to cyber dating abuse. To measure perceived social norms with regard to cyber dating abuse, the respondents were asked with three items how they perceived that their friends who were important in their lives would evaluate cyber dating abuse behaviors, ranging from $1=$ strongly disapprove to $4=$ strongly approve (Cronbach's $\alpha=.76)$. The items were based on behaviors that were included in the control dimension of the Cyber Dating Abuse Questionnaire (Borrajo et al., 2015). The items included: (a) accessing e-mail messages and messages on the partner's cell phone and social networking accounts without his or her consent, (b) sending the romantic partner a message via the Internet or mobile phone to check what the partner was doing, and (c) controlling the pictures of the romantic partner as well as the people with whom he or she became friends on social networking sites. Mean scores were used in further analysis $(M=2.39 ; S D=.61)$.

\section{Observation of controlling behaviors perpetrated by fathers and observation of} controlling behaviors perpetrated by mothers. A self-constructed scale that measured controlling behaviors by the father asked respondents to indicate whether they had observed the following behaviors: (a) my father calls his wife/girlfriend regularly to inquire about where she is, (b) my father makes negative comments about what his wife/girlfriend has bought, (c) my father controls the e-mail or cell phone of his wife/girlfriend, and (d) my father does not allow his wife/girlfriend to go out with certain friends, or he makes comments about this (Cronbach's $\alpha=.66)$. The respondents were asked about their father's current or most recent relationship (or used to have) with his wife/girlfriend. The participants were asked the frequency of these behaviors on a scale from $1=$ never to $5=$ very often.

The scale measuring controlling behaviors by the participants' mother asked the respondents to indicate whether they had observed their mother perpetuate controlling 
behaviors (Cronbach's $\alpha=.66$ ) during her current or most recent romantic relationship. The items were similarly worded to the previous scale, and the word "father" was replaced by the word "mother." The mean scores were used in further analysis $\left(M_{\text {father }}=1.58 ; S D=0.63\right.$; $\left.M_{\text {mother }}=1.56 ; S D=0.60\right)$.

Gender stereotypes. Five items from the gender stereotyping dimension of the Dating Violence Norms scale (Foshee et al., 2001) were used to measure the extent to which adolescents held gender stereotypical attitudes (Cronbach's $\alpha=.74)$. The respondents were asked to rate four statements regarding gender stereotypes on a 6-point Likert scale on a scale from $1=$ completely disagree to $6=$ completely agree. The statements included: (a) in a dating relationship, the boy should be smarter than the girl; (b) girls are always trying to manipulate boys; (c) swearing is worse for a girl than for a boy; (d) on a date, the boy should be expected to pay all expenses; and (e) it is more important for boys than girls to do well in school. Mean scores were used in further analysis $(M=2.37 ; S D=.92)$.

Control variables. The gender $(0=$ male $; 1=$ female $)$, age $($ in years $)$, and living situation ( $0=$ living with both parents, $n=300,67.0 \% ; 1=$ other living situation with at least one of the parents, $n=148,33.0 \%$ ) of the respondents were obtained. The last category, namely living with at least one parent, could include "living with father and his new partner," "living with mother and her new partner," "living with mother alone," "living with father alone," "alternating between living with father and mother". Respondents $(n=18)$ who indicated that they lived in a situation other than with at least one of their parents were removed from the further analyses, as this might have impacted their ability to witness interparental controlling behaviors. Furthermore, the length of the respondents' relationship was obtained by indicating "how long they had been together" with their current romantic 
partner, on a scale from $0=$ less than a week to $5=$ more than 6 months $(M=4.22 ; S D=$ 1.20). These variables were used as control variables in the analysis.

\section{Analytic Strategy}

The data were analyzed using SPSS Version 24.00 (IBM Corp., Armonk, NY, USA) in two steps. In the first step, standard multiple regression was used to assess which of the independent variables were associated with engagement in digital monitoring behaviors. All of the independent variables were entered simultaneously. The correlations between the theoretical variables are presented in Table 2, and the regression model is presented in Table 3.

\section{Results}

The total explained variance of the model was $26.2 \%$. The perceived social norms of the peers with regard to the behavior were the most important correlate of engagement in digital monitoring behaviors $(\beta=.35, p<.001)$, thus confirming H1. Also confirming our expectation (H2a), observing controlling behaviors by one's father $(\beta=.13, p<.05)$ was significantly associated with digital monitoring behaviors. Contrary to our expectations (H2b), observing controlling behaviors by the mother was not associated with cyber dating abuse perpetration $(\beta=.03, p=.522)$. In line with our third hypothesis $(\mathrm{H} 3)$, higher endorsement of gender stereotypes $(\beta=.15, p<.001)$ was linked to engagement in digital monitoring behaviors.

Among the control variables, age $(\beta=.13, p<.01)$ and gender $(\beta=.16, p<.01)$ were found to be significant correlates of engagement in digital monitoring behaviors, with females and older adolescents being more likely to engage in these behaviors. The relationship length $(\beta=.06, p=.134)$ and living situation $(\beta=.02, p=.559)$ were not significantly associated with engagement in online monitoring behaviors. 
Insert Tables 2 and 3 about here

\section{Discussion}

Because of the widespread use of digital technologies, perpetrators of dating violence have new and additional ways to target their victims (Zweig et al., 2014). Cyber dating abuse differs from traditional dating violence in that it might be more difficult for the victim to escape from online forms of abuse and that some perpetrators might experience less inhibitions from engaging in the abuse (Van Ouytsel, Walrave, et al., 2016). The current literature on cyber dating abuse is rather descriptive in nature and lacks a theoretical perspective that could aid the development of prevention and intervention efforts. By adopting a social learning perspective, this study explains the correlates of digital monitoring behaviors by exploring how abusive behaviors are learned and how they are shaped by witnessing controlling behaviors among young people's parents and through their peer group's norms and the perpetrators' own attitudes.

Similar to previous research on adolescent risk behavior, perceived social norms were the most important correlates of adolescents' engagement in digital monitoring behaviors (Cochran et al., 2015; Heirman \& Walrave, 2012; Van Ouytsel et al., 2017). It appears that perpetrators of cyber dating abuse often associate themselves with peers who hold similar attitudes toward the behavior. In this aspect, cyber dating abuse perpetration is comparable to other types of online deviant behavior such as engagement in cyberbullying or sexting. The perceived approval of peers has also been found to predict adolescents' engagement in these behaviors (Heirman \& Walrave, 2012; Van Ouytsel et al., 2017). 
This study also found that adolescents who perceived that their father engaged in offline controlling behaviors were also more likely to engage in cyber dating abuse than those who did not. The findings extend previous research on offline forms of dating violence, which found associations between witnessing interparental violence and adolescents perpetrating dating violence (Arriaga \& Foshee, 2004; Foshee et al., 1999; Malik et al., 1997; O'Keefe, 1997; Schwartz et al., 1997), and they provide further evidence that perceptions of intimate parental relationships can also shape adolescents' own behaviors (Allen \& Mitchell, 2015). Family relationships also appear to influence online behaviors among adolescents. The findings of our study suggest that youth who grow up witnessing controlling behaviors by their fathers might believe that such behaviors are an appropriate way to cope with concerns about faithfulness and jealousy in their own romantic relationships.

As expected, adolescents' endorsement of gender stereotypes was significantly related to the perpetration of digital monitoring and controlling behaviors. This is in line with previous studies on the associations between holding gender stereotypes and engagement in dating violence among adolescents (McCauley et al., 2013; Reed et al., 2011; Reyes et al., 2016). Adolescents who hold gender stereotypical attitudes might also endorse gendered scripts with regard to dating. For instance, girls might feel insecure about their romantic relationships and be more likely to believe that boys are less likely to be faithful and more sexually promiscuous (Marston \& King, 2006; Tolman, Spencer, Rosen-Reynoso, \& Porche, 2003). They might resort to digital monitoring behaviors as a means of protecting their romantic relationship (Lucero et al., 2014; Stonard et al., 2015). On the other hand, adolescent males might endorse a similar stereotype and belief that other boys pose a threat to their relationships, which can fuel the need to engage in controlling their romantic partners through digital media as well. 


\section{Implications for Practice}

The descriptive results of our study reveal that $39.4 \%$ of our respondents had read their partner's e-mail messages or messages at least once in the six months prior to the study on their cell phone or on social networking site accounts without their partner's permission. Previous qualitative research has found that adolescent couples often share passwords with each other or access their partner's accounts through their partner's cell phones when their partner forgets to log out or leaves the room (Lucero et al., 2014; Rueda, Lindsay, \& Williams, 2015; Van Ouytsel et al., 2016). Prevention efforts could address how unauthorized access to private messages violates the privacy of a romantic partner and how adolescents can protect themselves against this type of abuse. They could stress the risks associated with sharing passwords, such as the unwanted publication of private information and cyberbullying victimization, and provide practical advice about how to protect their personal data (Walrave \& Heirman, 2011). Moreover, prevention efforts could also focus on the potential legal consequences of certain aspects of cyber dating abuse, as unauthorized access to someone else's e-mail could be punishable under data protection legislation. Adolescent females in our study and previous research were found to be more likely to engage in digital monitoring and controlling behaviors than male adolescents (Baker \& Helm, 2011; Lucero et al., 2014; Stonard et al., 2015; Zweig et al., 2013). Some young people might believe that it is more socially acceptable for females to engage in online monitoring of their romantic partner than males (Lucero et al., 2014; Zweig et al., 2013).

Our finding that perceived social norms are the most important correlate of engagement in digital monitoring behaviors highlights the need for prevention efforts to address and reduce the influence of these norms. Some strategies could include addressing these group norms and the norms surrounding cyber dating abuse as well as teaching adolescents how to deal with peer pressure with regard to online monitoring of their romantic 
partner (e.g., not engaging in the behavior when their friends might advise them to do so). Moreover, the fact that witnessing interparental controlling behaviors is associated with online monitoring behaviors further underscores the need for prevention efforts to focus on ways to discuss and diminish the influence of abusive behaviors within the family context.

The finding that endorsement of gender stereotypes is associated with engagement in online monitoring behaviors highlights the need for prevention and intervention efforts to discuss and challenge the traditional gender stereotypical beliefs that might facilitate dating violence. Extending previous research on offline forms of dating abuse, our study found that gender stereotypical beliefs are also associated with cyber dating abuse perpetration.

Prevention efforts could focus on strategies to help adolescents express their concerns about the faithfulness of their romantic partner in more appropriate ways than resorting to digital monitoring and controlling behaviors (e.g., by teaching them how to communicate openly and how to deal with these feelings).

\section{Limitations and Directions for Future Research}

Several limitations should be noted when interpreting the results. First, this study is cross-sectional, which does not allow us to establish causal relationships. Longitudinal research is warranted to investigate the causality of these relationships. The second limitation is the reliance on self-reports and the use of retrospective measures for cyber dating abuse perpetration and the observation of abusive behaviors among parents. Although the researchers stressed the anonymity and confidentiality of the responses, the participants might have misreported their own behaviors or those of others because they did not recall the behaviors accurately. The third limitation is the use of a predominantly female convenience sample, which might limit the generalizability of our findings. Future studies might use alternative sampling methods to reduce potential bias. 
The fourth limitation of this study is the fact that we were unable to investigate cultural and ethnic diversity. While some studies have focused on abuse experiences in digital dating among specific cultural groups, such as Hawaiian adolescents (Baker \& Carreño, 2015) and Mexican American adolescents (Rueda, Lindsay, \& Williams, 2014; Rueda \& Williams, 2014), more research is needed on how culture could play a role in experiences of cyber dating abuse. Likewise, future studies could also investigate cyber dating abuse among sexual minority youth. Previous research has found that youth who identify as LGBTQ are at a much higher risk of victimization by other types of online risk behaviors such as cyberbullying (Finn, 2004; Schneider, O'Donnell, Stueve, \& Coulter, 2012) and online grooming (Wolak et al., 2008). To the best of our knowledge, there is currently a lack of research that investigates the extent to which these youth are confronted with digital forms of dating abuse. It will be one of the main frontiers of cyber dating abuse research to investigate the experiences of youth who identify themselves as a sexual minority with regards to cyber dating abuse.

Fifth, the current study only used a limited number of social learning variables. Future studies could include additional measures such as a detailed scale to measure the direct observation of abusive behaviors among siblings and good friends as well as a variable to measure adolescents' expectations with regard to the perpetration of digital monitoring behaviors (i.e., the theoretical construct of differential reinforcement). Also, future research could include measures on the perceived social norms that better capture the theoretical aspects of frequency, duration, intensity, and priority that individuals experience when they associate with important others. Follow-up research could also investigate a wider range of abusive online relationship behaviors, such as stalking or psychological forms of abuse (e.g., insulting the partner online or publishing private information), as the current study only focused on digital monitoring behaviors. While this study investigates the perpetration of cyber dating abuse from the perspective of social learning theory, other studies could apply additional 
theoretical frameworks to further enhance our understanding of the social and individual context in which cyber dating abuse perpetration takes place, such as general strain theory (Agnew, 2014), cognitive dissonance theory (Festinger, 1962), and the theory of planned behavior (Ajzen, 1991).

Finally, the extent to which the adolescents would describe these behaviors as abusive themselves is unknown, as previous research found that they might interpret digital monitoring and controlling behaviors as signs of love and care as opposed to abusive behavior (Baker \& Helm, 2010). Future studies could, for instance, investigate adolescents' perceptions of cyber dating abuse by providing them with different vignettes to see how they would evaluate and categorize different behaviors that would be considered abuse by scholarly definitions of cyber dating abuse.

Despite these limitations, this study fills a gap in the literature by addressing the need to apply a theoretical perspective when studying cyber dating abuse perpetration. The study found that perceived positive group norms, witnessing controlling behaviors within the family, and the endorsement of gender stereotypes were significantly linked with cyber dating abuse perpetration. The findings have implications for practice and underscore the need for prevention efforts to discuss group norms about cyber dating abuse. Moreover, such efforts should focus on diminishing the impact of gender stereotypical attitudes and the influence of types of abusive behaviors within the family context. 


\section{References}

Agnew, R. (2014). General Strain Theory. In G. Bruinsma \& D. Weisburd (Eds.), Encyclopedia of Criminology and Criminal Justice (pp. 1892-1900): Springer New York.

Ajzen, I. (1991). The theory of planned behavior. Organizational behavior and human decision processes, 50(2), 179-211.

Akers, R. L., \& Jennings, W. (2009). Social Learning Theory. In J. Miller (Ed.), 21st Century criminology: A reference handbook (pp. 323-332). Thousand Oaks: Sage Publications, Inc.

Akers, R. L., Krohn, M. D., Lanza-Kaduce, L., \& Radosevich, M. (1979). Social Learning and Deviant Behavior: A Specific Test of a General Theory. American Sociological Review, 44(4), 636-655. doi:10.2307/2094592

Allen, K., \& Mitchell, S. (2015). Perceptions of Parental Intimate Relationships and Their Affects on the Experience of Romantic Relationship Development Among African American Emerging Adults. Marriage \& Family Review, 51(6), 516-543. doi:10.1080/01494929.2015.1038409

Arriaga, X. B., \& Foshee, V. A. (2004). Adolescent Dating Violence: Do Adolescents Follow in Their Friends', Or Their Parents', Footsteps? Journal of Interpersonal Violence, 19(2), 162-184. doi:10.1177/0886260503260247

Baker, C., \& Carreño, P. (2016). Understanding the Role of Technology in Adolescent Dating and Dating Violence. Journal of Child and Family Studies, 25(1), 308-320. doi:10.1007/s10826-015-0196-5

Baker, C. K., \& Helm, S. (2010). Pacific Youth and Shifting Thresholds: Understanding Teen Dating Violence in Hawai'i. Journal of School Violence, 9(2), 154-173. doi:10.1080/15388220903585879 
Baker, C. K., \& Helm, S. (2011). Prevalence of intimate partner violence victimization and perpetration among youth in Hawai'i. Hawaii medical journal, 70(5), 92-96.

Baker, C. R., \& Stith, S. M. (2008). Factors Predicting Dating Violence Perpetration Among Male and Female College Students. Journal of Aggression, Maltreatment \& Trauma, 17(2), 227-244. doi:10.1080/10926770802344836

Bandura, A. (1977). Social Learning Theory. Englewood Cliffs, NJ: Prentice-Hall.

Bandura, A., Ross, R., \& Ross, S. (1962). Transmission of aggression through imitation of aggressive models. Journal of Abnormal and Social Psychology, 63, 575-582.

Borrajo, E., Gámez-Guadix, M., Pereda, N., \& Calvete, E. (2015). The development and validation of the cyber dating abuse questionnaire among young couples. Computers in Human Behavior, 48, 358-365. doi:10.1016/j.chb.2015.01.063

Cochran, J. K., Maskaly, J., Jones, S., \& Sellers, C. S. (2015). Using Structural Equations to Model Akers' Social Learning Theory With Data on Intimate Partner Violence. Crime \& Delinquency. doi:10.1177/0011128715597694

Dardis, C. M., Dixon, K. J., Edwards, K. M., \& Turchik, J. A. (2015). An Examination of the Factors Related to Dating Violence Perpetration Among Young Men and Women and Associated Theoretical Explanations: A Review of the Literature. Trauma, Violence, \& Abuse, 16(2), 136-152. doi:10.1177/1524838013517559

Dick, R. N., McCauley, H. L., Jones, K. A., Tancredi, D. J., Goldstein, S., Blackburn, S., . . . Miller, E. (2014). Cyber Dating Abuse Among Teens Using School-Based Health Centers. Pediatrics. doi:10.1542/peds.2014-0537

Festinger, L. (1962). A Theory of Cognitive Dissonance (Vol. 2). Stanford, CA, USA: Stanford University Press.

Finn, J. (2004). A Survey of Online Harassment at a University Campus. Journal of Interpersonal Violence, 19(4), 468-483. doi:10.1177/0886260503262083 
Foshee, V. A., Bauman, K. E., \& Linder, G. F. (1999). Family Violence and the Perpetration of Adolescent Dating Violence: Examining Social Learning and Social Control Processes. Journal of Marriage and Family, 61(2), 331-342. doi:10.2307/353752

Foshee, V. A., Linder, F., MacDougall, J. E., \& Bangdiwala, S. (2001). Gender Differences in the Longitudinal Predictors of Adolescent Dating Violence. Preventive Medicine, 32(2), 128-141. doi: 10.1006/pmed.2000.0793

Heirman, W., \& Walrave, M. (2008). Assessing concerns and issues about the mediation of technology in cyberbullying. Cyberpsychology: Journal of Psychosocial Research on Cyberspace, 2(2), 1-12.

Heirman, W., \& Walrave, M. (2012). Predicting adolescent perpetration in cyberbullying : an application of the theory of planned behavior. Psicothema, 24(4), 614-620.

Heyman, R. E., \& Slep, A. M. S. (2002). Do Child Abuse and Interparental Violence Lead to Adulthood Family Violence? Journal of Marriage and Family, 64(4), 864-870. doi:10.1111/j.1741-3737.2002.00864.x

Lichter, E. L., \& McCloskey, L. A. (2004). The effects of childhood exposure to marital violence on adolescent gender-role beliefs and dating violence. Psychology of Women Quarterly, 28(4), 344-357. doi:10.1111/j.1471-6402.2004.00151.x

Lucero, J. L., Weisz, A. N., Smith-Darden, J., \& Lucero, S. M. (2014). Exploring Gender Differences: Socially Interactive Technology Use/Abuse Among Dating Teens. Affilia, 29(4), 478-491. doi:10.1177/0886109914522627

Malik, S., Sorenson, S. B., \& Aneshensel, C. S. (1997). Community and dating violence among adolescents: Perpetration and victimization. Journal of Adolescent Health, 21(5), 291302. doi: 10.1016/S1054-139X(97)00143-2 
Manchikanti Gómez, A. (2011). Testing the Cycle of Violence Hypothesis: Child Abuse and Adolescent Dating Violence as Predictors of Intimate Partner Violence in Young Adulthood. Youth \& Society, 43(1), 171-192. doi:10.1177/0044118x09358313

Marston, C., \& King, E. (2006). Factors that shape young people's sexual behaviour: a systematic review. The Lancet, 368(9547), 1581-1586. doi: 10.1016/S01406736(06)69662-1

McCauley, H. L., Tancredi, D. J., Silverman, J. G., Decker, M. R., Austin, S. B., McCormick, M. C., . . . Miller, E. (2013). Gender-Equitable Attitudes, Bystander Behavior, and Recent Abuse Perpetration Against Heterosexual Dating Partners of Male High School Athletes. American Journal of Public Health, 103(10), 1882-1887. doi:10.2105/AJPH.2013.301443

O'Keefe, M. (1997). Predictors of Dating Violence Among High School Students. Journal of Interpersonal Violence, 12(4), 546-568. doi:10.1177/088626097012004005

Peskin, M. F., Markham, C. M., Shegog, R., Temple, J. R., Baumler, E. R., Addy, R. C., .. . Emery, S. T. (2017). Prevalence and Correlates of the Perpetration of Cyber Dating Abuse among Early Adolescents. Journal of Youth and Adolescence, 46(2), 358-375. doi:10.1007/s10964-016-0568-1

Reed, E., Silverman, J. G., Raj, A., Decker, M. R., \& Miller, E. (2011). Male Perpetration of Teen Dating Violence: Associations with Neighborhood Violence Involvement, Gender Attitudes, and Perceived Peer and Neighborhood Norms. Journal of Urban Health : Bulletin of the New York Academy of Medicine, 88(2), 226-239. doi:10.1007/s11524-011-9545-X

Reed, L. A., Tolman, R. M., \& Safyer, P. (2015). Too close for comfort: Attachment insecurity and electronic intrusion in college students' dating relationships. Computers in Human Behavior, 50, 431-438. doi: 10.1016/j.chb.2015.03.050 
Reed, L. A., Tolman, R. M., Ward, L. M., \& Safyer, P. (2016). Keeping tabs: Attachment anxiety and electronic intrusion in high school dating relationships. Computers in Human Behavior, 58, 259-268. doi: 10.1016/j.chb.2015.12.019

Reyes, H. L., Foshee, V., Niolon, P., Reidy, D., \& Hall, J. (2016). Gender Role Attitudes and Male Adolescent Dating Violence Perpetration: Normative Beliefs as Moderators. Journal of Youth and Adolescence, 45(2), 350-360. doi:10.1007/s10964-015-0278-0

Rueda, H. A., Lindsay, M., \& Williams, L. R. (2015). "She Posted It on Facebook": Mexican American Adolescents' Experiences With Technology and Romantic Relationship Conflict. Journal of Adolescent Research, 30(4), 419-445. doi:10.1177/0743558414565236

Rueda, H. A., \& Williams, L. R. (2014). "It's not just you two": A grounded theory of peerinfluenced jealousy as a pathway to dating violence among acculturating Mexican American adolescents. Psychology of Violence, 4(3), 294-308. doi: 10.1037/a0034294

Sasson, H., \& Mesch, G. (2017). The Role of Parental Mediation and Peer Norms on the Likelihood of Cyberbullying. The Journal of Genetic Psychology, 178(1), 15-27. doi:10.1080/00221325.2016.1195330

Schwartz, M., O'Leary, S. G., \& Kendziora, K. T. (1997). Dating Aggression Among High School Students. Violence and Victims, 12(4), 295-305.

Schneider, S. K., O'Donnell, L., Stueve, A., \& Coulter, R. W. (2012). Cyberbullying, school bullying, and psychological distress: A regional census of high school students. American Journal of Public Health, 102(1), 171-177. doi: 10.2105/AJPH.2011.300308

Sears, H. A., Sandra Byers, E., \& Lisa Price, E. (2007). The co-occurrence of adolescent boys' and girls' use of psychologically, physically, and sexually abusive behaviours in their dating relationships. Journal of Adolescence, 30(3), 487-504. doi: 10.1016/j.adolescence.2006.05.002 
Sellers, C. S., Cochran, J. K., \& Branch, K. A. (2005). Social Learning Theory and Partner Violence: A Research Note. Deviant behavior, 26(4), 379-395. doi:10.1080/016396290931669

Shen, A. C.-T., Chiu, M. Y.-L., \& Gao, J. (2012). Predictors of Dating Violence Among Chinese Adolescents: The Role of Gender-Role Beliefs and Justification of Violence. Journal of Interpersonal Violence, 27(6), 1066-1089. doi:10.1177/0886260511424497

Simon, T. R., Miller, S., Gorman-Smith, D., Orpinas, P., \& Sullivan, T. (2010). Physical Dating Violence Norms and Behavior Among Sixth-Grade Students From Four U.S. Sites. The Journal of Early Adolescence, 30(3), 395-409. doi:10.1177/0272431609333301

Steinberg, L. (2011). Adolescence. 9th international edition. New York: McGraw-Hill Humanities.

Stonard, K. E., Bowen, E., Walker, K., \& Price, S. A. (2015). “They'll Always Find a Way to Get to You": Technology Use in Adolescent Romantic Relationships and Its Role in Dating Violence and Abuse. Journal of Interpersonal Violence. doi:10.1177/0886260515590787

Suler, J. (2004). The online disinhibition effect. CyberPsychology \& Behavior, 7(3), 321-326. doi:10.1089/1094931041291295

Temple, J. R., Choi, H. J., Brem, M., Wolford-Clevenger, C., Stuart, G. L., Peskin, M. F., \& Elmquist, J. (2016). The Temporal Association Between Traditional and Cyber Dating Abuse Among Adolescents. Journal of Youth and Adolescence, 45(2), 340-349. doi:10.1007/s10964-015-0380-3

Temple, J. R., Choi, H. J., Elmquist, J., Hecht, M., Miller-Day, M., Stuart, G. L., . . W WolfordClevenger, C. (2016). Psychological Abuse, Mental Health, and Acceptance of Dating Violence Among Adolescents. Journal of Adolescent Health, 59(2), 197-202. doi: 10.1016/j.jadohealth.2016.03.034 
Tolman, D. L., Spencer, R., Rosen-Reynoso, M., \& Porche, M. V. (2003). Sowing the Seeds of Violence in Heterosexual Relationships: Early Adolescents Narrate Compulsory Heterosexuality. Journal of Social Issues, 59(1), 159-178. doi:10.1111/1540-4560.t01$1-00010$

Utz, S., \& Beukeboom, C. J. (2011). The role of social network sites in romantic relationships: Effects on jealousy and relationship happiness. Journal of Computer-Mediated Communication, 16(4), 511-527. doi:10.1111/j.1083-6101.2011.01552.x

Van Ouytsel, J., Ponnet, K., Walrave, M., \& d'Haenens, L. (2017). Adolescent sexting from a social learning perspective. Telematics and Informatics, 34(1), 287-298. doi: dx.doi.org/10.1016/j.tele.2016.05.009

Van Ouytsel, J., Ponnet, K., \& Walrave, M. (2016). Cyber Dating Abuse Victimization Among Secondary School Students From a Lifestyle-Routine Activities Theory Perspective. Journal of Interpersonal Violence. Online ahead of print. doi:10.1177/0886260516629390

Van Ouytsel, J., Ponnet, K., Walrave, M., \& Temple, J. R. (2016). Adolescent cyber dating abuse victimization and its associations with substance use, and sexual behaviors. Public Health, 135, 147-151. doi: dx.doi.org/10.1016/j.puhe.2016.02.011

Van Ouytsel, J., Torres, E., Choi, H. J., Ponnet, K., Walrave, M., \& Temple, J. R. (2017). The Associations Between Substance Use, Sexual Behaviors, Bullying, Deviant Behaviors, Health, and Cyber Dating Abuse Perpetration. The Journal of School Nursing, 33(2), 116-122. doi:10.1177/1059840516683229

Van Ouytsel, J., Van Gool, E., Walrave, M., Ponnet, K., \& Peeters, E. (2016). Exploring the role of social networking sites within adolescent romantic relationships and dating experiences. Computers in Human Behavior, 55, Part A, 76-86. doi: dx.doi.org/10.1016/j.chb.2015.08.042 
Van Ouytsel, J., Walrave, M., Ponnet, K., \& Temple, J. R. (2016). Digital forms of dating violence - what school nurses need to know. NASN School Nurse. 31(6), 348-353. doi:10.1177/1942602x16659907

Walrave, M., \& Heirman, W. (2011). Cyberbullying: Predicting Victimisation and Perpetration. Children \& society, 25(1), 59-72. doi:10.1111/j.1099-0860.2009.00260.x

Wolak, J., Finkelhor, D., Mitchell, K. J., \& Ybarra, M. L. (2008). Online "Predators" and Their Victims. American Psychologist, 63(2), 111-128. doi:10.1037/0003-066X.63.2.111

Wolf, K. A., \& Foshee, V. A. (2003). Family Violence, Anger Expression Styles, and Adolescent Dating Violence. Journal of Family Violence, 18(6), 309-316. doi:10.1023/a:1026237914406

Yahner, J., Dank, M., Zweig, J. M., \& Lachman, P. (2014). The Co-Occurrence of Physical and Cyber Dating Violence and Bullying Among Teens. Journal of Interpersonal Violence. doi:10.1177/0886260514540324

Zweig, J., Lachman, P., Yahner, J., \& Dank, M. (2014). Correlates of Cyber Dating Abuse Among Teens. Journal of Youth and Adolescence, 43, 1306-1321. doi:10.1007/s10964013-0047-x

Zweig, J. M., Dank, M., Yahner, J., \& Lachman, P. (2013). The rate of cyber dating abuse among teens and how it relates to other forms of teen dating violence. Journal of Youth and Adolescence, 1063-1077. doi:10.1007/s10964-013-9922-8 
$\%$ of the

Type of cyber dating abuse perpetration

M SD $\begin{gathered}\text { respondents who } \\ \text { had engaged in }\end{gathered}$ the behavior

\begin{tabular}{lccc}
\hline $\begin{array}{l}\text { Accessed the e-mail messages, the messages on his/her cell phone } \\
\text { or social networking account without the partner's consent. }\end{array}$ & 1.62 & .93 & $39.4 \%$ \\
$\begin{array}{l}\text { Controlled when the partner was last online through applications } \\
\text { such as Facebook Messenger or Whats App. }\end{array}$ & 2.00 & 1.23 & $49.6 \%$ \\
$\begin{array}{l}\text { Sent messages via the internet or the mobile phone to check what } \\
\text { their partner was doing and with whom they were. }\end{array}$ & 1.77 & 1.02 & $45.8 \%$ \\
$\begin{array}{l}\text { Sent multiple messages or called in a row (5/10/20/30 times an } \\
\text { hour) to control where their partner was and with whom he/she was. }\end{array}$ & 1.40 & .80 & $24.8 \%$ \\
\hline
\end{tabular}

Table 1: Means, standard deviations and percentages of the respondents who had at least engaged once in the respective types of cyber dating abuse 
Table 2. Correlations Between the Research Constructs

\begin{tabular}{|c|c|c|c|c|c|}
\hline & 1 & 2 & 3 & 4 & 5 \\
\hline $\begin{array}{l}\text { Perceived social } \\
\text { norms of peers }\end{array}$ & - & & & & \\
\hline $\begin{array}{l}\text { Perception of } \\
\text { controlling behaviors } \\
\text { by father }\end{array}$ & $.20 * *$ & - & & & \\
\hline $\begin{array}{l}\text { Perception of } \\
\text { controlling behaviors } \\
\text { by mother }\end{array}$ & $.18^{* *}$ & $.46^{* *}$ & - & & \\
\hline Gender stereotypes & $.11^{*}$ & $.23 * *$ & $.21 * *$ & - & \\
\hline $\begin{array}{l}\text { Perpetration of } \\
\text { controlling behaviors }\end{array}$ & $.42 * *$ & $.24 * *$ & $.16^{* *}$ & $.18^{* *}$ & - \\
\hline
\end{tabular}

Note. ${ }^{*} p<.05, * * p<.01$ 
Table 3: Multiple linear regression coefficients predicting perpetration of controlling behaviors

\section{Perpetration of controlling behaviors}

\begin{tabular}{|c|c|c|c|c|c|}
\hline & $\mathrm{B}$ & SD & $\beta$ & t-value & $p$ \\
\hline \multicolumn{6}{|l|}{ Control variables } \\
\hline Gender & .27 & .08 & .16 & 3.50 & $* *$ \\
\hline Age & .11 & .04 & .13 & 3.06 & $* *$ \\
\hline Living situation & .04 & .07 & .02 & .58 & \\
\hline $\begin{array}{l}\text { Length of the romantic } \\
\text { relationship }\end{array}$ & .04 & .03 & .06 & 1.50 & \\
\hline \multicolumn{6}{|l|}{ Social learning variables } \\
\hline Perceived social norms of peers & .44 & .05 & .35 & 8.02 & $* * *$ \\
\hline $\begin{array}{l}\text { Perception of controlling } \\
\text { behaviors by father }\end{array}$ & .15 & .06 & .13 & 2.60 & $*$ \\
\hline $\begin{array}{l}\text { Perception of controlling } \\
\text { behaviors by mother }\end{array}$ & .04 & .06 & .03 & .64 & \\
\hline Gender stereotypes & .13 & .04 & .15 & 3.21 & $* *$ \\
\hline Constant & -2.29 & .66 & & -3.49 & $* *$ \\
\hline $\begin{array}{l}R^{2}=.26 \\
\text { Adjusted } R^{2}=.25\end{array}$ & & & & & \\
\hline
\end{tabular}

